\title{
QUEEN'S
UNIVERSITY
BELFAST
}

\section{Dynamically Reconfigurable UWB Antenna using a FET Switch Powered by Wireless RF Harvested Energy}

Quddious, A., Abbasi, M. A. B., Antoniades, M. A., Vryonides, P., Fusco, V., \& Nikolaou, S. (2020). Dynamically Reconfigurable UWB Antenna using a FET Switch Powered by Wireless RF Harvested Energy. IEEE

Transactions on Antennas and Propagation, 68(8), 5872-5881. https://doi.org/10.1109/TAP.2020.2988941

\section{Published in:}

IEEE Transactions on Antennas and Propagation

\section{Document Version:}

Peer reviewed version

\section{Queen's University Belfast - Research Portal:}

Link to publication record in Queen's University Belfast Research Portal

\section{Publisher rights}

(C) 2020 IEEE.

This work is made available online in accordance with the publisher's policies. Please refer to any applicable terms of use of the publisher.

\section{General rights}

Copyright for the publications made accessible via the Queen's University Belfast Research Portal is retained by the author(s) and / or other copyright owners and it is a condition of accessing these publications that users recognise and abide by the legal requirements associated with these rights.

\section{Take down policy}

The Research Portal is Queen's institutional repository that provides access to Queen's research output. Every effort has been made to ensure that content in the Research Portal does not infringe any person's rights, or applicable UK laws. If you discover content in the Research Portal that you believe breaches copyright or violates any law, please contact openaccess@qub.ac.uk. 


\title{
Dynamically Reconfigurable UWB Antenna using a FET Switch Powered by Wireless RF Harvested Energy
}

\author{
Abdul Quddious, Member, IEEE, Muhammad Ali Babar Abbasi, Member, IEEE, Marco A. \\ Antoniades, Senior Member, IEEE, Photos Vryonides, Member, IEEE, Vincent Fusco, Fellow, IEEE \\ and Symeon Nikolaou, Member, IEEE
}

\begin{abstract}
A dynamically reconfigurable dual-layer UWB antenna integrated with an energy harvesting system for powering a GaAs FET switch is presented. The UWB antenna dynamically creates a notch-band in the presence of an interfering signal at $5.6 \mathrm{GHz}$ and it goes back to normal UWB operation when the interferer is removed. For the switching operation, the FET switch is powered using only harvested energy carried by the interfering signals. The UWB antenna on the front layer is a microstrip-fed monopole with an embedded elliptical slot. Inside the slot a quarter wavelength linear stub acts as a resonator and it is connected and disconnected using the low-power FET switch. The UWB antenna shares the RF ground with a very compact energy harvesting system, that consists of a planar inverted-F antenna, a very compact voltage doubler rectifier and a passive DC-to-DC boost converter. The boost converter elevates the rectified voltage to above the $3.3 \mathrm{~V}$ threshold, which is the minimum voltage needed for the actuation of the FET switch. The dynamic notch-band reconfiguration of the UWB antenna without the need for any external DC power source is made possible when the collected power at the input of the rectifier is higher than $\mathbf{- 1 2} \mathrm{dBm}$.
\end{abstract}

Index Terms - Notch-Band UWB antenna, Reconfigurable, Rectifier, Wireless power transmission (WPT)

\section{INTRODUCTION}

$\mathrm{I}_{\mathrm{n}}^{\mathrm{n}}$ the past decade, Ultra-wideband (UWB) technology has received great attention due to the supported high data rates, the low transmitted power $(-44.3 \mathrm{dBm})$ requirements, and its inherent resistance to jamming and relative immunity to multipath fading $[1,2]$. Due to these advantages, it has been used in a wide range of different applications such as cognitive

Manuscript received XXX, revised XXX, and published XXX (projected). This work was supported in part by the European Union by the Erasmus Mundus INTACT doctoral level mobility program.

A. Quddious and M.A. Antoniades is with the Department of Electrical and Computer Engineering, University of Cyprus, 1 Panepistimiou Ave., Nicosia 2109, Cyprus (e-mail: quddious.abdul@ucy.ac.cy).

P. Vryonides and S. Nikolaou are with the Frederick University, and Frederick Research Center (FRC), 7, Y. Frederickou Str. Pallouriotisa, Nicosia 1036 Cyprus (e-mails: s.nikolaou@frederick.ac.cy).

M. Ali Babar Abbasi and V. Fusco are with The Centre for Wireless Innovation (CWI), The Institute of Electronics, Communications and Information Technology (ECIT), School of Electronics, Electrical Engineering and Computer Science (EEECS), Queen's University Belfast, Belfast BT3 9DT, United Kingdom (email: m.abbasi@qub.ac.uk). radio [3], short-range in-house communications, wireless sensor networks, healthcare and biomedical wireless systems [4], sensing and imaging systems [5], radar detecting and target locating [6] and IoT applications [7, 8].

Unavoidably, UWB systems share the same spectrum with several other narrowband wireless systems which use subbands within the Federal Communication Commission (FCC) defined UWB range which covers the spectrum of 3.1-10.6 $\mathrm{GHz}$ [9]. The FCC mask limits the UWB EIRP to -41.3 $\mathrm{dBm} / \mathrm{MHz}$, which means that wirelessly transmitted UWB signals are rather weak, and therefore they do not substantially affect the performance of the co-existing communication systems. The most popular and most congested band is the 5 GHz IEEE $802.11 \mathrm{a} / \mathrm{h} / \mathrm{j} / \mathrm{n}$ WLAN systems using several narrow sub-bands between 5 and $6 \mathrm{GHz}(5.15-5.35 \mathrm{GHz}, 5.25-5.35$ $\mathrm{GHz}, 5.47-5.725 \mathrm{GHz}, 5.725-5.825 \mathrm{GHz})$. In order to suppress the unintentional received interfering signals and improve the associated SNR, UWB antennas are designed with notch-bands, which effectively filter out the received signals. UWB antennas with single-, dual- and multi band notches have been reported $[4,10,11]$. A number of methods are used to achieve a bandnotched UWB antenna like to embed slots, add resonators on the radiator, or the feeding line, or even create perturbations on the RF ground $[4,10,11]$.

In order to make the notch-band UWB antennas reconfigurable, electrical switches are used to connect and disconnect antenna parts. Some designs have used PIN diodes $[3,12]$ to switch the notch ON/OFF, varactor diodes [13] for continuously tunable designs, radio frequency microelectromechanical systems (RF-MEMS) $[14,15]$ and GaAs field effect transistors (FET) [16] to achieve reconfigurability. In general, all these electrical switches need direct-current (DC) power to bias the switch components which means that a battery is required with the antenna module. Depending on the preferred switch the biasing conditions may vary significantly. The biasing voltage for the RF-MEMS (30-90 V) and varactors $(0-33 \mathrm{~V})$ is considerably higher as compared to PIN diodes $(0.3-0.9 \mathrm{~V})$, however PIN diodes require a higher biasing current ( $\mathrm{mA}$ range) and the overall DC biasing power required is in the range of $\mathrm{mW}$. 


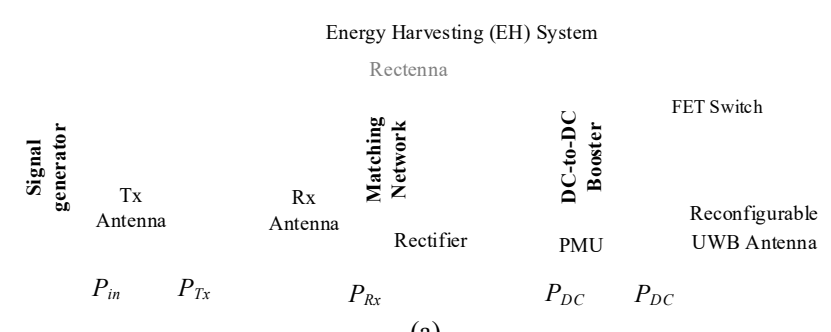

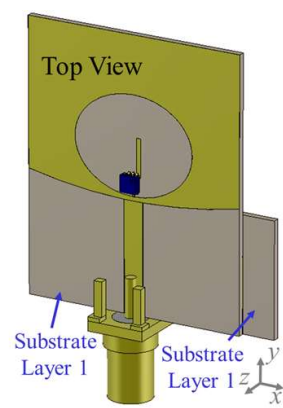

(b)

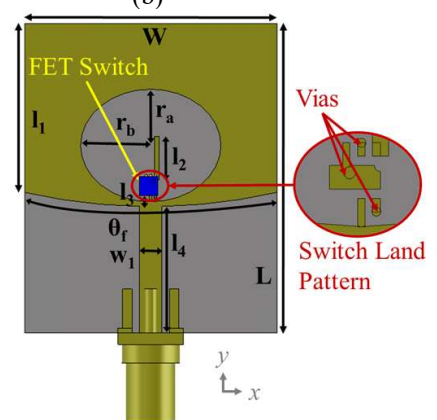

(d) (a)

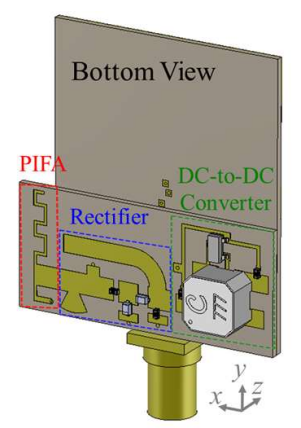

(c)

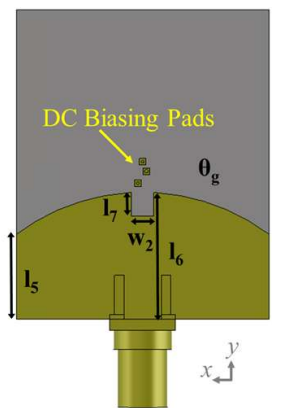

(e)

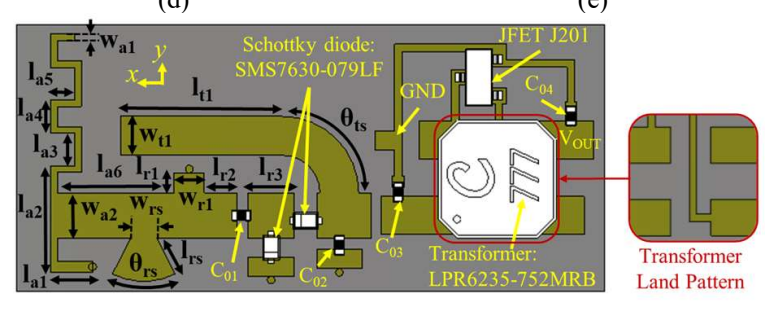

(f)

Fig 1. (a). Block diagram of the dynamically reconfigurable UWB antenna's operation. Proposed UWB monopole antenna diagram: (b) and (c) System-onPackage (SoP) perspective view (d) front view, (e) rear view (d) Rectenna module.

Investigating the implementation of a battery-less switching solution, to be powered using harvested RF energy, a FET switch was considered since it requires a biasing DC power in the order of $\mu \mathrm{W}$ [17]. Furthermore, GaAs FET switches have a very low insertion loss compared to PIN diodes. The current manuscript presents a UWB antenna with an integrated energy harvesting $(\mathrm{EH})$ circuit that allows the dynamic switching of the notch-band without the need for an external DC power source. The notch is created dynamically when an interfering signal is detected and it disappears when the interfering signals become undetectable. This is accomplished by exploiting the RF energy carried by the interfering signals, which is converted to DC using a high efficiency RF-to-DC rectifier. The rectified DC voltage drives a passive DC-to-DC boost converter to elevate the DC voltage, and when the DC voltage reaches $3.3 \mathrm{~V}$ it
TABLE I SCHEMATIC DIMENSIONS

\begin{tabular}{l|llllll}
\hline \multicolumn{7}{c}{ UWB Antenna } \\
\hline Parameter & $\mathrm{W}$ & $\mathrm{L}$ & $\mathrm{l}_{1}$ & $\mathrm{l}_{2}$ & $\mathrm{l}_{3}$ & $\mathrm{l}_{4}$ \\
Value $(\mathrm{mm})$ & 27.0 & 33.0 & 18.0 & 6.5 & 1.15 & 13.5 \\
\hline Parameter & $1_{5}$ & $1_{6}$ & $1_{7}$ & $\mathrm{~W}_{1}$ & $\mathrm{~W}_{2}$ & $\mathrm{r}_{\mathrm{a}}$ \\
Value $(\mathrm{mm})$ & 9.1 & 13.6 & 2.5 & 2.4 & 2.4 & 6.0 \\
\hline Parameter & $\mathrm{r}_{\mathrm{b}}$ & $\theta_{\mathrm{f}}$ & $\theta_{\mathrm{g}}$ \\
Value $(\mathrm{mm})$ & 7.5 & 27.3 & 28.6 & & & \\
\hline \multicolumn{7}{c}{ Rectenna } \\
\hline Parameter & $1_{\mathrm{a} 1}$ & $1_{\mathrm{a} 2}$ & $1_{\mathrm{a} 3}$ & $1_{\mathrm{a} 4}$ & $1_{\mathrm{a} 5}$ & $1_{\mathrm{a} 6}$ \\
Value $(\mathrm{mm})$ & 2.2 & 5.6 & 1.7 & 1.77 & 1.27 & 6.15 \\
\hline Parameter & $1_{\mathrm{r} 1}$ & $\mathrm{l}_{\mathrm{r} 2}$ & $1_{\mathrm{r} 3}$ & $1_{\mathrm{t} 1}$ & $1_{\mathrm{rs}}$ & $\mathrm{W}_{\mathrm{a} 1}$ \\
Value $(\mathrm{mm})$ & 1.05 & 1.72 & 2.4 & 8.54 & 2.1 & 3.00 \\
\hline Parameter & $\mathrm{W}_{\mathrm{a} 2}$ & $\mathrm{~W}_{\mathrm{a} 1}$ & $\mathrm{~W}_{\mathrm{rs}}$ & $\mathrm{W}_{\mathrm{r} 1}$ & $\mathrm{~W}_{\mathrm{ts}}$ & $\theta_{\mathrm{rs}}$ \\
Value $(\mathrm{mm})$ & 0.6 & 2.40 & 1.32 & 1.32 & 1.32 & 60 \\
\hline \hline
\end{tabular}

actuates a FET switch on the UWB radiator, thus dynamically creating a notch-band at the frequency of the interferer. The development of a very compact and highly efficient RF-to-DC rectifier as part of a complete energy harvesting circuit was necessary.

For the proposed dual-layer dynamically reconfigurable UWB antenna presented in this work, a dual-layer concept was adopted and is presented schematically in Figs 1(b) and 1(c). The dual-layer module consists of a reconfigurable UWB antenna using a single low-power FET switch on one layer and an integrated very compact energy harvesting system consisting of a PIFA antenna with a high efficiency RF-to-DC rectifier (operating at narrow band $5.6 \mathrm{GHz}$ WLAN frequency), cascaded with a passive DC-to-DC boost converter on the other layer. To the best of our knowledge, such a reconfigurable UWB antenna with dynamic battery-less reconfigurability, using switch powered entirely from RF harvested energy, is presented for the first time.

\section{ReCONFIGURABLE UWB ANTENNA DESIGN}

The geometry of the UWB monopole antenna with the embedded elliptical slot is illustrated in Fig. 1. The UWB antenna was fabricated on a Rogers RT/duroid 5880 substrate board (relative permittivity $\varepsilon_{\mathrm{r}}=2.2$, and loss tangent tan $\delta=$ 0.0009 ) with overall board dimensions $33(\mathrm{~L}) \times 27(\mathrm{~W}) \times 0.787$ (h) $\mathrm{mm}^{3}$.

A $2.4 \mathrm{~mm}$ wide, microstrip line resulting in $50 \Omega$ characteristic impedance is used to feed the UWB antenna. For matching improvement, the radiating patch and the RF ground patch have rounded corners. This contributes towards a smoother transition from the propagating modes to the radiated modes which affects the matching [13]. The matching is also improved with the addition of a rectangular cut with a size of $l_{7} \times w_{2}$ at the top edge of the curved ground placed under the microstrip line on the back side of the substrate (see Fig. 1(d)). For better agreement between the simulated and measured results the SMA connector was included in the simulation model.

An elliptical-slot on the radiating patch is introduced, this has a dual function. On the one hand it further improves the matching as can be seen in Fig. 2. On the other hand, without increasing the overall antenna size, it provides sufficient space for the integration of the linear $\lambda / 4 \mathrm{stub}$, which causes the band- 


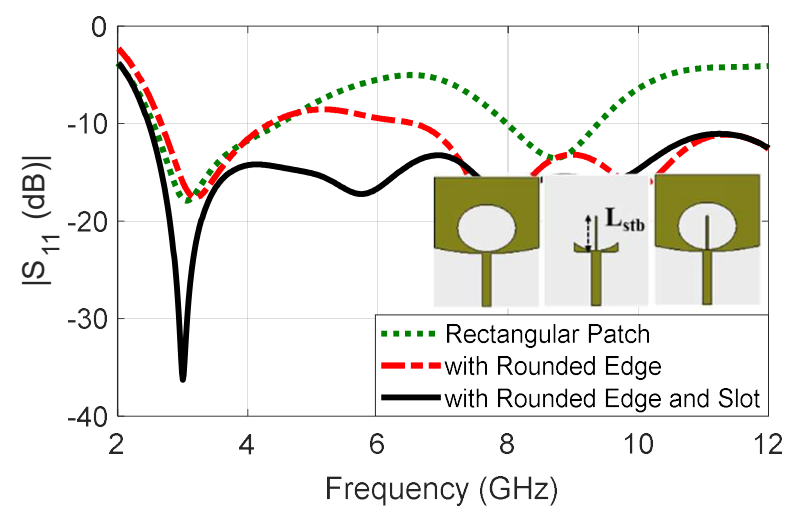

Fig. 2: Reflection coefficient corresponding to three initial design stages of the proposed UWB antenna without notch band.

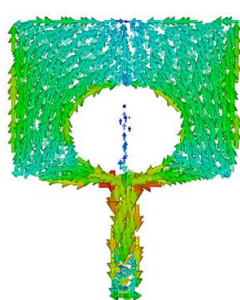

(a)
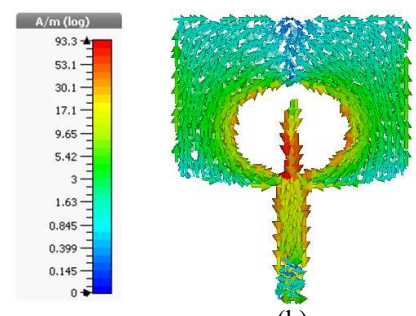

(b)

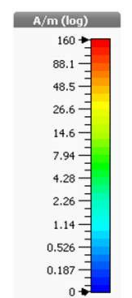

Fig. 3. Surface current distributions of the reconfigurable UWB antenna at 5.6 $\mathrm{GHz}$, when the FET switch is (a) "OFF" and (b) "ON".

notch response. The effect of the rounded corners and the addition of an elliptical slot on the matching can also be seen in Fig. 2. Compared to the initial model that used rectangular patches for both the radiator and the ground (green dotted line) the combination of the elliptical slot on the radiator and the rounded edge ground (black line) improves the impedance matching significantly.

The elliptical slot provides the required space for the addition of a $\lambda / 4$ stub (at 5-6 GHz) which causes a bandstop filter response in the same frequency range which is congested by several applications. The bandstop filter response can be added on the conventional UWB antenna response automatically and immediately once an interfering signal stronger than $-12 \mathrm{dBm}$ is received. For the generation of notch, the use of an external DC power source or any other control signal are not required.

Figs 1(c) and 1(d) present the proposed antenna schematic with the used dimensions which are summarized in Table I. For the electronic switching, a single pole, double-throw (SPDT) GaAs FET switch from Skyworks [18] is used (SKY13298360LF). This switch can be driven directly by a $3.3 \mathrm{~V}$ DC voltage without the need for a bias network or a blocking capacitor, and it is suitable for frequencies from 3 to $8 \mathrm{GHz}$. For the biasing of the FET switch, vias are used which connect the front side where the FET is incorporated with small square pads of $1 \times 1 \mathrm{~mm}^{2}$ on the back side of the antenna where the energy harvesting circuit resides. The use of vias replaces the use of DC wires which may perturb the radiation pattern of the antenna. The total DC power consumption of the GaAs FET switch is very low $(<16 \mu \mathrm{W})$. The required DC voltage is provided from DC-to-DC boost converter that is introduced in a subsequent section. CST Microwave Studio was used for the

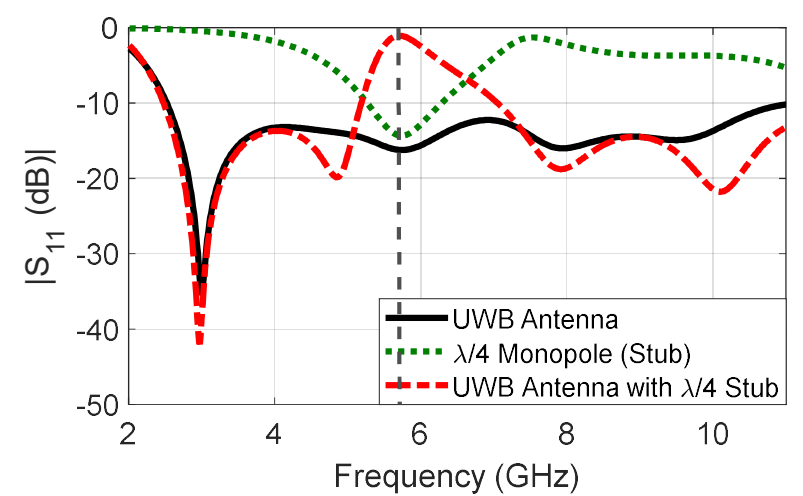

Fig. 4: Reflection coefficient corresponding to three initial design stages of the proposed band- notched UWB antenna. The corresponding schematics are shown in the inset.

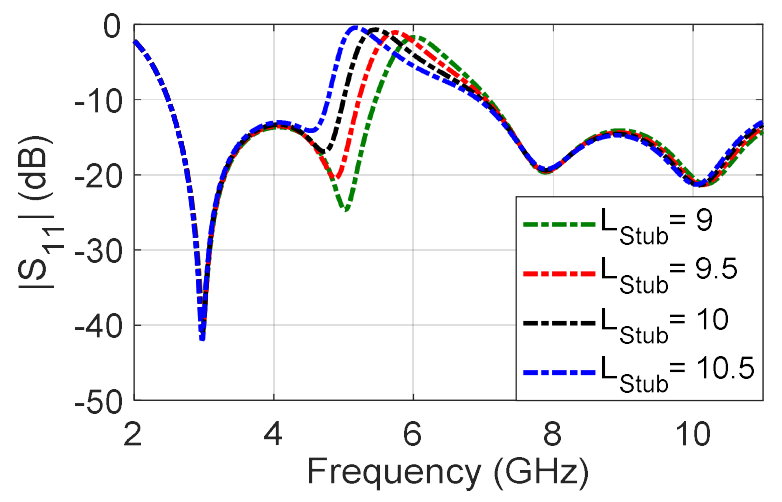

Fig. 5. Simulated $\left|S_{11}\right|$ for different values of stub length $L_{\text {stb }}$.

full wave simulations and complementary co-simulations using S-parameters files (.s3p) for the FET switch in both "ON" and "OFF" states, were carried out in Design Studio.

\section{BAND REJECTION}

The simulated surface current distribution at $5.6 \mathrm{GHz}$, the central frequency of the notch-band, can be seen in Fig. 3 when the switch is in "ON" or "OFF" state. With the switch in "ON" state the current distribution concentrates on the stub and as a result, a notch is created on $\left|\mathrm{S}_{11}\right|$ along with a significant decrease in the measured gain as can be verified from the subsequently presented in Fig. 9.

The geometric characteristics of the stub (length, width and position) directly affect the frequency and the quality of the notch band. The position and length of the stub are chosen in such a way to directly connect it to the $50 \Omega$ feedline and thus resemble a standalone $\lambda / 4$ planar monopole resonator. The resonance frequency of a $\lambda / 4$ planar monopole can be approximated by [19]:

$$
\begin{gathered}
f_{R}=\frac{c \times 0.24}{\left(h_{e q}+r_{e q}\right) \times \sqrt{\varepsilon_{e f f}}} \\
h_{e q}=L_{\text {monopole }}=L_{s t b} \\
r_{e q}=\frac{W_{\text {monopole }}}{2 \pi}
\end{gathered}
$$

Where, $c$ is the speed of light, $h_{e q}$ and $r_{e q}$ are the equivalent height and radius. The calculated resonance frequency $5.6 \mathrm{GHz}$ using equation (1), (2) and (3) with $h_{e q}=9.75 \mathrm{~mm}, r_{e q}=$ 


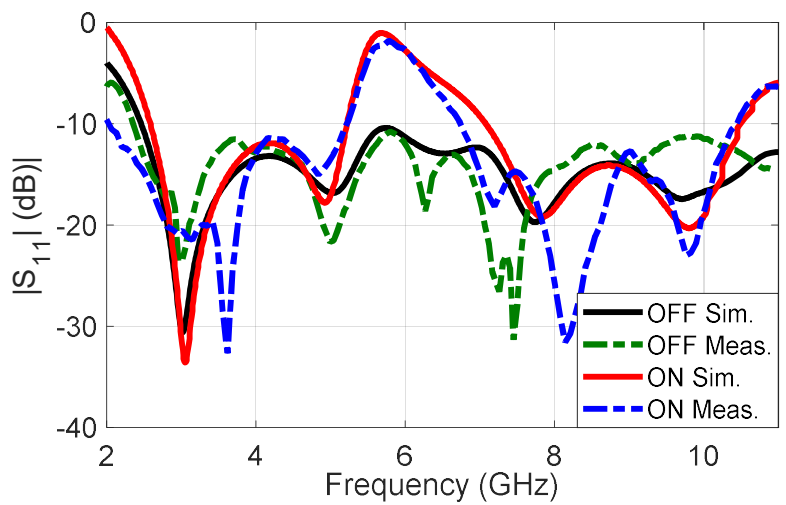

Fig. 6. Simulated and measured $\left|\mathrm{S}_{11}\right|$ of the reconfigurable UWB antenna for both cases when the FET switch is "OFF" and "ON".
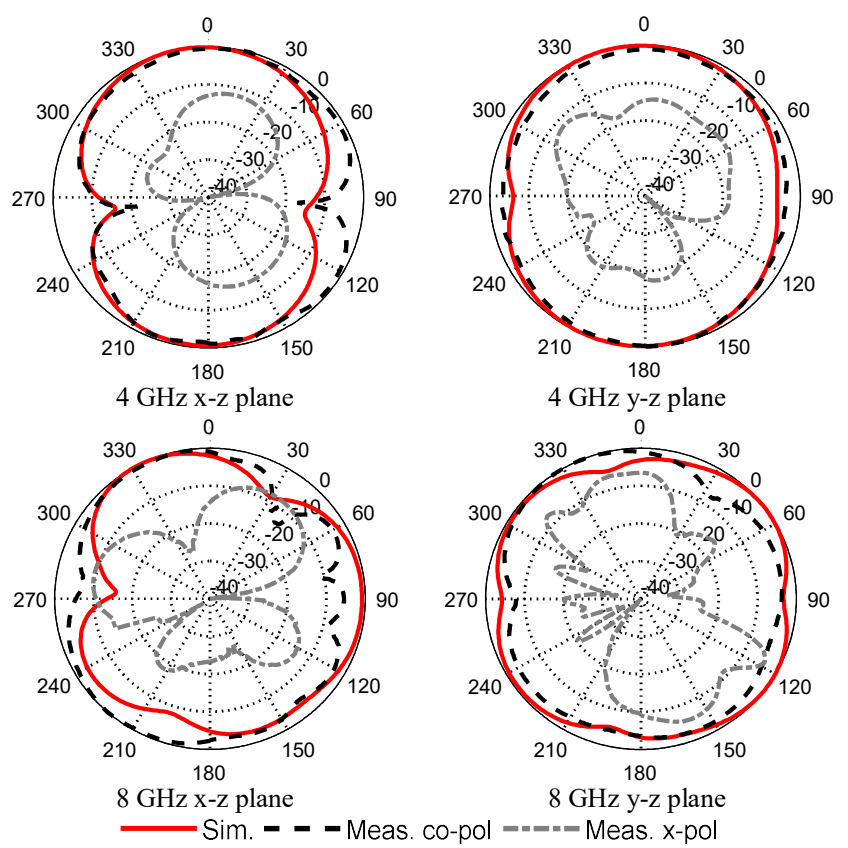

Fig. 7 Simulated and measured normalized radiation patterns in the E- (x-z) and $\mathrm{H}-(\mathrm{y}-\mathrm{z})$ planes at $4 \mathrm{GHz}$ and $8 \mathrm{GHz}$ with the FET switch in the "ON" state.

$0.078 \mathrm{~mm}$ and $\varepsilon_{\text {eff }}=1.738$. Fig. 4 . shows that the simulated reflection coefficient for the $\lambda / 4$ planar monopole resonator (green dotted line) has the same resonance frequency as the calculated one (indicated by the vertical grey dashed line). By placing this $\lambda / 4$ planar monopole in the elliptical slot of the UWB antenna, and by electrically connecting it to the feedline using the FET switch causes a notch at 5.6 GHz. It should be noted that the $h_{e q}=L_{s t b}$ value comprises the overall length of the rectangular stub including the length of the FET switch, and it can be seen in the inset of Fig. 4. The final dimensions for the fine-tuned optimized stub are $L_{s t b}=9.65 \mathrm{~mm}$ and $w=$ $0.5 \mathrm{~mm}$. From Fig. 5, it can be seen that the center frequency and the peak of the notch-band are controlled by the physical dimensions of the stub. The stub parameters can be modified to demonstrate a practical implementation of the presented antenna concept when it is required to reject signals from the $5.0 \mathrm{GHz}$ IEEE $802.11 \mathrm{y}$ HIPERLAN/2 band $(5.470-5.725 \mathrm{GHz})$ and the $5 \mathrm{GHz}$ IEEE $802.11 \mathrm{a} / \mathrm{h} / \mathrm{j} / \mathrm{n}$ WLAN band $(5.15-5.35$ $\mathrm{GHz}, 5.25-5.35 \mathrm{GHz}, 5.47-5.725 \mathrm{GHz}$ and $5.725-5.825 \mathrm{GHz})$.
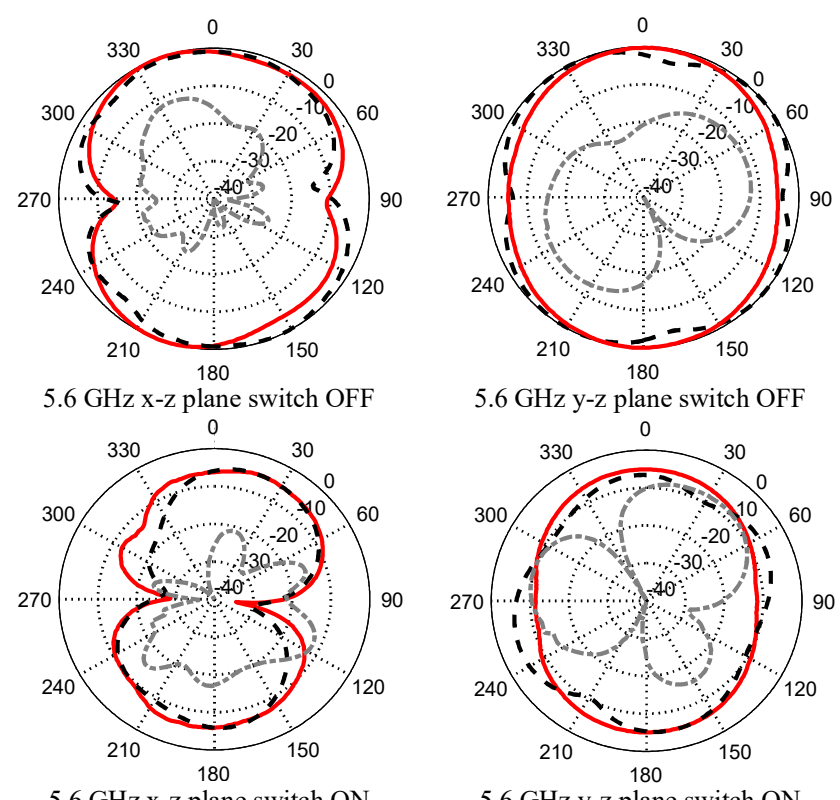

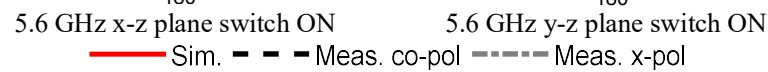

Fig. 8. Simulated and measured normalized radiation patterns in the E- $(x-z)$ and $\mathrm{H}-(\mathrm{y}-\mathrm{z})$ planes at $5.6 \mathrm{GHz}$ with the FET switch in the "OFF" and "ON" state.

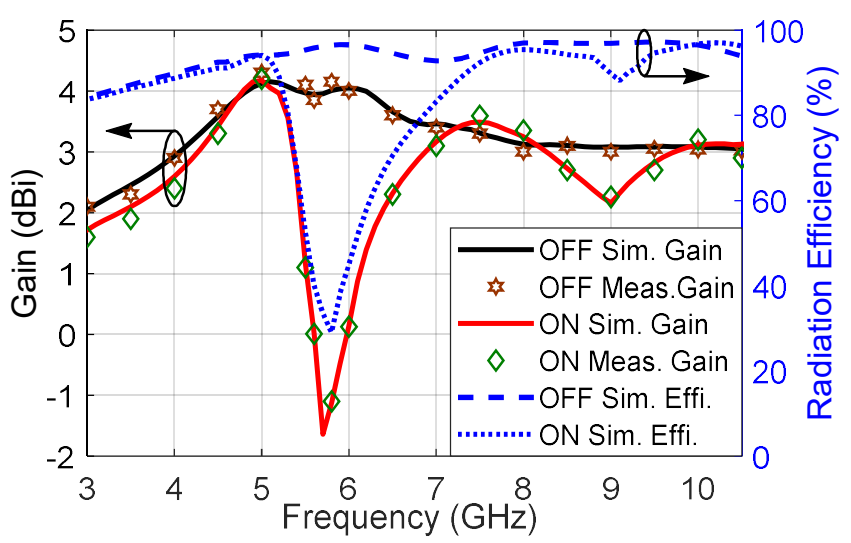

Fig. 9. Simulated and measured realized gain with simulated radiation efficiency of the proposed UWB antenna as function of frequency for both "ON" and "OFF" states.

This effectively creates a notch band which can suppress signals from 5.0- 6.0 GHz.

\section{UWB ANTENNA MEASUREMENT RESUlts}

$S$-parameter and radiation pattern measurements were taken for the prototype device. A direct comparison between the simulated reflection coefficient and the measured one with the switch in either state, is presented in Fig. 6. When the lowpower FET switch is set to the "OFF" state a typical UWB antenna response is observed while the FET switch in "ON" state creates a frequency notch between $5 \mathrm{GHz}$ and $6.5 \mathrm{GHz}$. It should be emphasized that this happens in an automatic and dynamic way when an interfering signal higher than $-12 \mathrm{dBm}$ is received. Agilent E8363B vector network analyzer (VNA) was used for the S-parameter measurements which are in very good agreement with the simulated results.

Far field radiation pattern measurements with the FET switch in "ON" state are presented in Fig. 7. The plots measured for 4 
and $8 \mathrm{GHz}$ indicate that the resonating element does not significantly affect the antenna radiation performance at frequencies other than $5.6 \mathrm{GHz}$. On the other hand, setting the FET switch to the "ON" state has a direct effect on the maximum gain of the antenna at $5.6 \mathrm{GHz}$. Fig. 8. presents the far-field radiation pattern at $5.6 \mathrm{GHz}$ for both the "ON" and "OFF" states. H-plane (y-z plane) patterns are mostly omnidirectional, while the E-plane ( $\mathrm{x}-\mathrm{z}$ plane) patterns have the typical shape for monopole-like radiators for every frequency. Note that the simulated patterns presented in Figs 7 and 8 follow the same Cartesian coordinate system depicted in Fig. 1. The measurements were conducted in NSI anechoic chamber using the same relevant coordinate system. The radiation pattern gain degradation observed from the normalized patterns in Fig. 8 is verified in Fig. 9, which presents the antenna peak realized gain values and efficiency versus frequency. The effective gain decrease at the notch frequency $(5.6 \mathrm{GHz})$ is verified for both simulated and measured gain values, which present remarkable agreement.

\section{ENERGy HarVesting (EH) SyStem}

In order to dynamically bias the FET switch, an Energy Harvesting $(\mathrm{EH})$ system was implemented and integrated on the back side of the reconfigurable UWB antenna. Although the required power for the actuation of the GaAs FET switch is very low $(<16 \mu \mathrm{W})$ it still needs a minimum of $3.3 \mathrm{~V}$, current consumption is estimated to be $5 \mu \mathrm{A}$. This DC voltage level cannot be achieved by the rectifier, therefore a second DC-toDC converter is needed. The implemented energy harvesting circuit consists of a PIFA antenna, a rectifier and a passive DCto-DC boost converter. The antenna and the rectifier operate at $5.6 \mathrm{GHz}$ and the implemented rectenna receives the RF incident signal and converts it into a DC voltage, which is subsequently further raised by the cascaded DC-to-DC boost converter. The FET switch of the UWB antenna is biased directly from the output of the DC-to-DC boost converter and this way when the FET is set to the "ON" state, it dynamically creates the notch, exploiting the harvested RF power of the received interfering signal. The 5.6 GHz RF signals which are part of the desired UWB signal are very low in power and they remain undetected from the rectenna. When the UWB antenna operates as a transmitter, an enabling signal is required to cancel the biasing of the FET switch and prevent the creation of the notch. The layout diagram of the rectenna with the cascaded DC-to-DC boost converter can be seen in Fig. 1(e), while the fabricated prototype mounted on the back side of the reconfigurable UWB antenna can be seen in Fig. 18 (b).

\section{A. Rectenna}

To accommodate the dual-layer microstrip technology with the rather limited available space on the second layer (the back side of the UWB antenna), without affecting its radiation performance, a very compact antenna for the energy harvesting system had to be selected. Considering the requirements for a very compact design and omni-directional radiation performance, a standard meandered planar inverted-F antenna (PIFA) [20, 21] was designed (Fig. 10). In addition to its

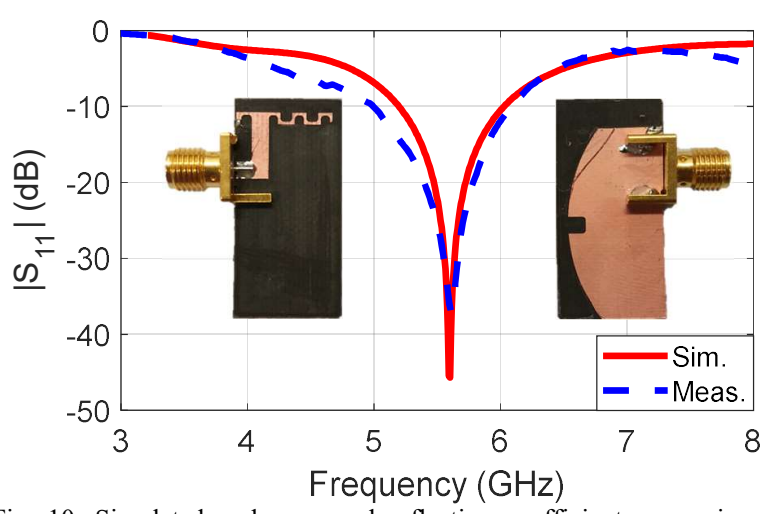

Fig. 10. Simulated and measured reflection coefficient comparison of the compact PIFA. The fabricated prototype of the antenna is shown in the inset photograph.
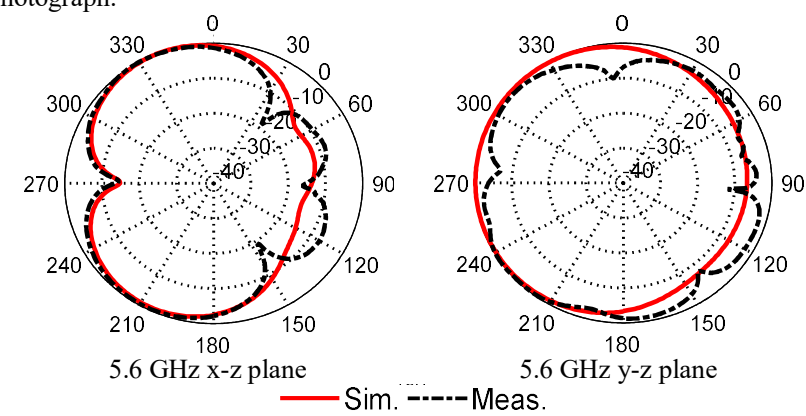

Fig. 11. Simulated and measured normalized radiation patterns of the compact PIFA in the E- $(x-z)$ and $\mathrm{H}-(\mathrm{y}-\mathrm{z})$ planes at $5.6 \mathrm{GHz}$.

compact size, the antenna had to be wideband enough to cover the entire frequency range from 5 to $6 \mathrm{GHz}$. The designed PIFA consisting of a meandered strip of width $w_{a l}=0.3 \mathrm{~mm}$, was the result of a rigorous multi-goal optimization process performed in CST Microwave Studio that resulted in the physical dimensions which are summarized in Table I. The PIFA is extended beyond the edge of the common RF ground with the UWB radiator. The same Rogers RT/duroid 5880 substrate was used for the PIFA as the one used for the UWB antenna. The primary design goal was to achieve a high radiation efficiency using a very compact $\left(2.5 \times 12.5 \mathrm{~mm}^{2}\right)$ footprint area. The feeding point of the antenna was selected keeping in mind that it needs to be part of a rectenna system and a DC-to-DC booster to implement a compact complete energy harvesting system. For testing purposes a stand-alone PIFA was fabricated and measured. The implemented PIFA with identical RF ground with the UWB antenna can be seen in the inset of Fig. 10 with the S-parameter measurements of the antenna. The $\left|\mathrm{S}_{11}\right|<-10$ $\mathrm{dB}$ bandwidth of the antenna, covers the range of 5-6.1 GHz, overlapping with the frequency bands used for the most common interfering applications. Fig. 11 shows the simulated and measured normalized radiation patterns of the PIFA antenna (following the same Cartesian coordinate system followed as shown in Fig. 1). It can be seen that the antenna produces a fairly omnidirectional radiation pattern which is required when the interfering signals have random directions of arrival. The simulated radiation efficiency at $5.6 \mathrm{GHz}$ was $98 \%$, and the maximum realized gain was $4.3 \mathrm{~dB}$. Note that the value of gain generally has a direct relation with the antenna footprint 


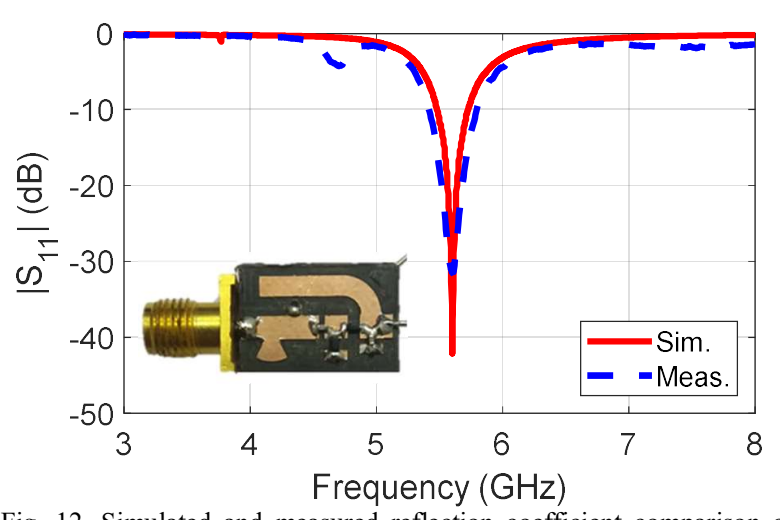

Fig. 12. Simulated and measured reflection coefficient comparison of the rectifier. The fabricated prototype of the rectifier is shown in the inset photograph.

so a directive antenna having larger footprint and the same efficiency can enhance the value of $P_{i n}$.

Considering the design constraints, the primary objective was a very compact circuit footprint that could use the rounded UWB antenna ground patch and provide a high RF-to-DC efficiency for varying input power levels $(-25 \mathrm{dBm}$ to $0 \mathrm{dBm})$. The rectifier was designed as part of the complete energy harvesting circuit and as the intermediate component between the PIFA and the passive DC-to-DC boost converter. The desired increased efficiency for the lower end of the incident power range led to the selection of a voltage-doubler topology with Schottky diodes. The low-cost Schottky diode SMS7630079LF [22] from Skyworks was selected, and the Keysight Advanced Design System (ADS) software was used for harmonic-balance (HB) and large signal S-parameter (LSSP) simulations to analyze the non-linear behaviour of the rectifier circuit. The rectifier bandwidth is defined by the matching network, therefore a distributed element matching network was preferred for enhanced bandwidth. The rectifier's efficiency was optimized considering the termination load to be $3.9 \mathrm{~K} \Omega$ which matches the input impedance of the subsequent DC-toDC boost converter. The design parameters are summarized in Table I and Fig. 12 presents the reflection coefficient and the fabricated rectifier prototype. Efficiency is defined in (4) where, $P_{\text {out }}$ and $P_{\text {in }}$ are the DC output power and the RF input levels, respectively, and $V_{d c}$ is the rectified voltage across the terminals of the load, $R_{L}$.

$$
\eta=\frac{P_{o u t}}{P_{i n}}=\frac{V_{d c}^{2} / R_{L}}{P_{i n}} \times 100 \%
$$

The voltage doubler topology includes two capacitors. The optimized values for $\mathrm{C}_{01}$ and $\mathrm{C}_{02}$ were $82 \mathrm{pF}$ and $120 \mathrm{pF}$, respectively. For input power at $-12 \mathrm{dBm}$ the measured return loss is more than $10 \mathrm{~dB}$ from 5.4 to $5.8 \mathrm{GHz}$ (measured bandwidth of $400 \mathrm{MHz}$ ). For efficiency measurements, the $\mathrm{R} \& \mathrm{~S} \AA \mathrm{SMF} 100 \mathrm{~A}$ signal generator was used to generate the signals that fed the rectifier. The rectified DC voltage across the $R_{L}$ was recorded while the power of a single tone $5.6 \mathrm{GHz}$ signal was varied from $-27 \mathrm{dBm}$ to $0 \mathrm{dBm}$. Fig. 13 presents the

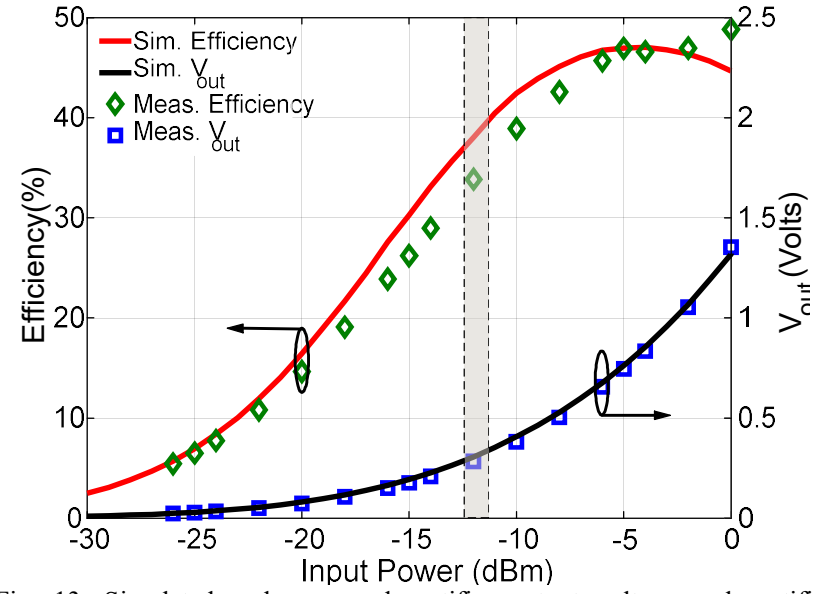

Fig. 13. Simulated and measured rectifier output voltage and rectifie efficiency versus input power at $5.6 \mathrm{GHz}$ across a $3.9 \mathrm{k} \Omega$ load resistance.

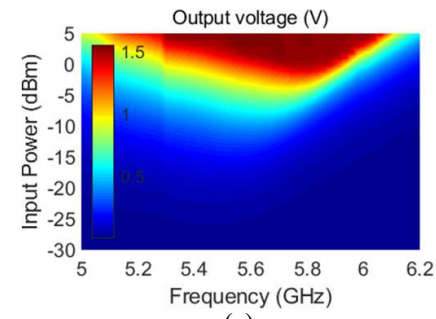

(a)

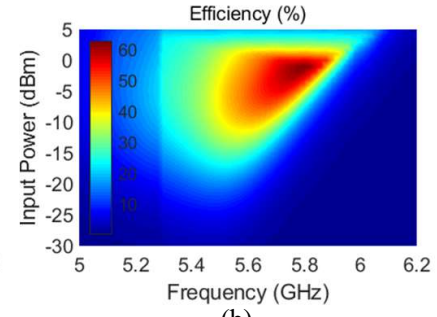

(b)
Fig. 14. Simulated (a) output voltage and (b) efficiency versus input power of the proposed rectifier as a function of frequency.

TABLE II

PERFORMANCE COMPARISON OF DIFFERENT RECTIFIERS

\begin{tabular}{cccccc}
\hline \hline Ref. & $\begin{array}{c}\text { Freq. } \\
(\mathrm{GHz})\end{array}$ & $\begin{array}{c}P_{\text {in }} \\
(\mathrm{dBm})\end{array}$ & Efficiency & Size $\left(\mathrm{cm}^{2}\right)$ & $\begin{array}{c}\text { Normalized } \\
\text { Size* }\end{array}$ \\
\hline This & $\mathbf{5 . 6}$ & $\mathbf{- 1 0}$ & $\mathbf{4 0 \%}$ & $\mathbf{1 . 5} \times \mathbf{1 . 0}$ & $\mathbf{1}$ \\
work & & 16.5 & $52 \%$ & $7.2 \times 4.2$ & 20.2 \\
{$[23]$} & 5.6 & 10 & $51.5 \%$ & $3.5 \times 2.6$ & 6.07 \\
{$[24]$} & 5.4 & $-10,1$ & $20 \%, 39.2 \%$ & $4.5 \times 3.0$ & 9.00 \\
{$[25]$} & 5.8 & 8 & $69.4 \%$ & $4.0 \times 4.0$ & 10.7 \\
{$[26]$} & 5.8 & $-10,0$ & $15 \%, 52.0 \%$ & - & - \\
{$[27]$} & 5.9 & 0 & $49.2 \%$ & $5 \times 2$ & 6.67 \\
{$[28]$} & 5.8 & 0 & & \\
\hline
\end{tabular}

*Normalized by $1.5 \mathrm{~cm}^{2}$

measured rectified voltage and the corresponding efficiency in comparison with the simulated results. Equation (4) was used for the efficiency calculation. Measurements indicate that the efficiency varies from $\sim 30 \%$ at $-15 \mathrm{dBm}$ up to $\sim 46 \%$ at $-5 \mathrm{dBm}$. The performance and the size of the implemented rectifier is compared with previously reported rectifiers in Table II. The variations of the efficiency and the output voltage over a wide frequency range can be seen in Fig. 14. It can be observed that the used rectifier has generally a good efficiency at low input powers $(40 \%$ at $-10 \mathrm{dBm})$, and at the same time it is the most compact design, in comparison with other designs which are listed in Table II. The next smallest rectifier [24] has an area that is 6 times larger than the circuit footprint of the proposed rectifier. As can be verified from Fig. 15 the efficiency of the rectifier depends non-linearly on the termination load which in this case is the input impedance of the subsequent DC-to-DC boost converter. For the simulated efficiency presented in Fig. $15, R_{L}$ was varied from $100 \Omega$ to $1 \mathrm{M} \Omega$ while varying input power levels were used. The rectifier's efficiency was 


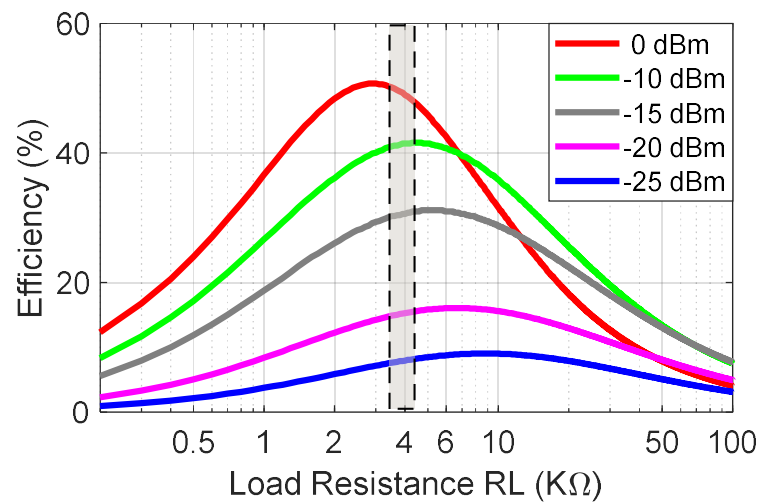

Fig. 15. Simulated rectifier efficiency versus output load for multiple input power levels from -25 to $0 \mathrm{dBm}$ at $5.6 \mathrm{GHz}$.

\section{DC-DC converter}

\begin{tabular}{|c|c|c|}
\hline $\mathrm{V}_{\text {in }}$ & 1 & LPR6235-752SMRB \\
\hline $\begin{array}{c}\text { DSP } \\
\text { enabling } \\
\text { signal }\end{array}$ & $\mathrm{OFF} / \mathrm{ON}{ }^{\mathrm{C}_{1}}$ & \\
\hline
\end{tabular}

JFET

J201

Fig. 16. Schematic diagram of the passive low-voltage and ultra-low power converter with $\mathrm{L}_{1}=7.5 \mu \mathrm{H}, \mathrm{C}_{2}=1 \mathrm{nF}$ and $\mathrm{C}_{2}=1 \mu \mathrm{F}$.

optimized to have its peak efficiency for termination load 3.9 $\mathrm{k} \Omega$ which is very close to the input impedance of the passive DC-to-DC boost converter.

\section{B. Passive DC-to-DC Boost Converter}

In order to actuate the SKY13298-360LFA GaAs FET switch, a control DC voltage of $3.3 \mathrm{~V}$ in combination with a 5 $\mu \mathrm{A}$ current, are needed. In this section, an ultra-low power passive DC-to-DC boost converter is presented that was needed in order to boost the rectifier's output DC voltage from a few milli volts to a few volts. The Armstrong oscillator [29] inspired the design of the converter. The passive DC-to-DC boost converter used in this work is an ultra-low-voltage, selfpowered converter. The converter schematic is shown in Fig. 16. At the input stage an AND gate can be added which can use the Vin and an enabling signal from the DSP as inputs. The DSP creates a logic zero when the UWB transceiver is in transmission mode and thus the DC-to-DC converter will not elevate the Vin voltage to the level which sets the FET switch on. As a result, the notch will not appear when the UWB antenna is used as a transmitter. For the implemented circuit in Fig. 19(b) the AND gate was not included since the UWB antenna was tested as a receiver. The used converter has three major functional blocks. The first block is a voltage stepping up Coilcraft "LPR6235-752SMRB" transformer. The second block consists of a J201 JFET which also uses the coupling inductors $\mathrm{L}_{1}$ and $\mathrm{L}_{2}$ of the transformer. The third block is the gate-source PN junction of the JFET, used as a diode to rectify the JFET's gate oscillations. These three functional blocks work simultaneously to form an Armstrong oscillator, working as a DC-to-DC converter. The low Gate-Source cut-off voltage $\left(V_{P}\right)$ and the low drain current (IDSs) of the JFET satisfy the oscillation's start-up conditions. When the initial stage of the

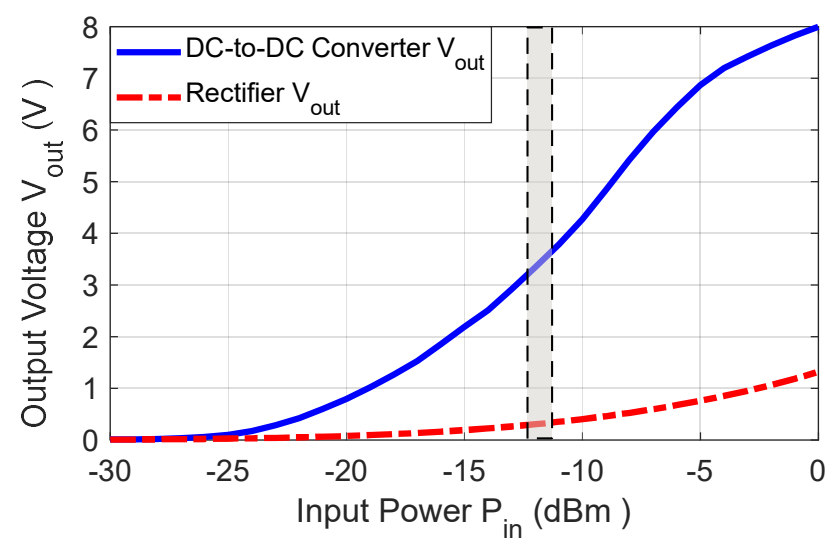

Fig. 17. Measured DC output voltage for the passive DC-to-DC boost converter and for the RF-to-DC rectifier.

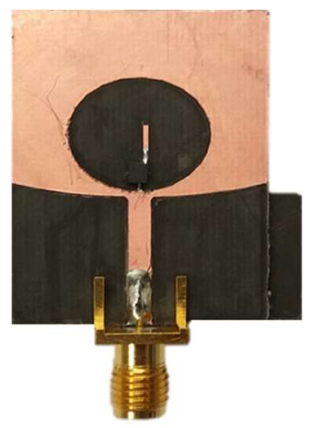

(a)

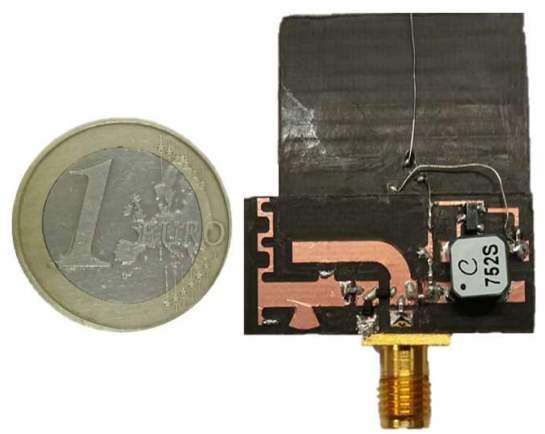

(b)
Fig 18. Fabricated prototype (a) front view showing the reconfigurable UWB monopole antenna, and (b) rear view showing the RF energy harvesting system consisting of the rectenna and the passive DC-to-DC boost converter.

transformer is connected to the output terminal of the rectifier, the current rises on the primary coil $\mathrm{L}_{1}$ and it induces a voltage on the secondary winding, applying a positive voltage on the normally-on $\mathrm{N}$ channel gate of the JFET. The PN junction between gate and source is conducting, therefore the output capacitor $\left(C_{2}\right)$ starts to charge with a negative voltage. Upon saturation of the primary current, the voltage across the primary coil is led to zero. Simultaneously, the negative voltage of the output capacitor is enforced on the JFET's gate, eventually pinching it off. As a result, the primary coil current is decreased and an opposite sign voltage is applied by the secondary coil on the gate of the JFET, which sets the switch to the "OFF" state. When the maximum voltage that switched-off the JFET returns to zero the cycle of oscillation is repeated.

Fig. 17 shows the measured DC output voltage across the output capacitor $\left(C_{2}\right)$ at the output stage of the passive DC-to-DC converter in comparison with the input DC voltage from the output of the rectifier. The rectifier with input RF power $\left(P_{i n}\right)$ equal to $-12 \mathrm{dBm}$ (set at the signal generator during testing) results in a rectified voltage at the output of the rectifier equal to $0.31 \mathrm{~V}$, which in turn results in a boosted voltage of $3.3 \mathrm{~V}$ at the output of the DC-to-DC converter, as can be seen in the highlighted region of Fig. 17. This boosted voltage is applied through the vias directly on the FET and causes its actuation. Although the available power at the FET switch is smaller than the power at the output of the rectifier, the omission of the passive DC-to-DC boost converter is not feasible. It is needed in order to deliver the combination of the high DC voltage with 


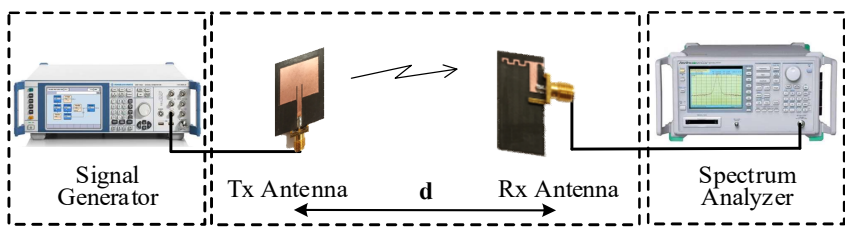

(a)

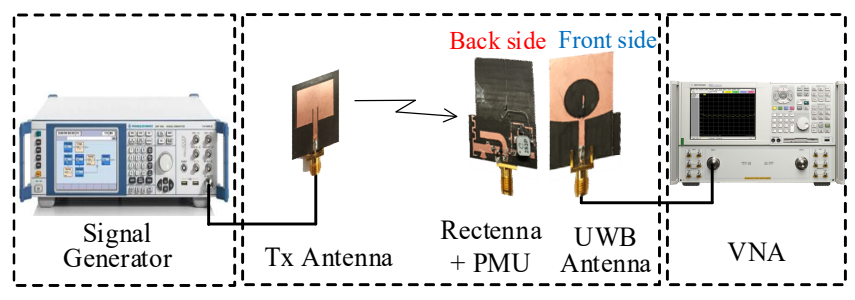

(b)

Fig. 19. Measurement setup. (a) Step 1 to define the input RF power of the rectifier, (b) Step 2 to calculate the rectified DC power at the output of the passive DC-to-DC boost converter and to measure the resulting $\left|\mathrm{S}_{11}\right|$ for the reconfigurable UWB antenna.

the low current ( $\mu \mathrm{A}$ range) that eventually causes the effective switching of the FET.

\section{IMPLEMENTATION AND TESTING}

\section{A. Implementation}

Fig. 18 shows the fabricated prototype of the battery-less UWB antenna with the dynamically reconfigurable notch powered from the EH system. On the front side (Fig. 18(a)), the UWB monopole with the FET switch can be seen, while the rear view (Fig. 18(b)) shows the integrated energy harvesting circuit in a System-on-Package (SoP) approach. Both the UWB antenna and the energy harvesting system were fabricated with a milling machine (LPKF ProtoMat H100) on two distinct Rogers RT/duroid 5880 boards. The GaAs FET switch (Skyworks SKY13298-360LF [18]) was soldered on the first board with the help of the LPKF ProtoPlace on the designated IC land patterns shown in Fig. 1 (c), while the SMS7630 [22] Schottky diodes and the capacitors (Murata series GJM03$82 / 120 \mathrm{pF}$ [30]) were added on the second board for the implementation of the rectifier component. Finally, a voltage step up transformer (Coilcraft LPR6235-752SMRB [31]) with a J201 JFET and $1 \mathrm{nF}$ capacitor were mounted on the EH system board for the passive DC-to-DC boost converter implementation. The two boards were placed back-to-back and were stuck together with low-loss glue so that the rounded RF ground patches of the two boards coincided with each other.

\section{B. Testing}

For the testing of the SoP reconfigurable UWB antenna the setup of Fig. 19 was used. In Step 1 (Fig. 19(a)), the received RF power $\left(P_{R X}\right)$ from the PIFA was measured using a spectrum analyzer (Anritsu MS2668C) to define the received input RF power to the rectifier, at a given distance d. A microstrip rectangular patch antenna [32] with realized gain $7.6 \mathrm{dBi}$ and radiation efficiency $97 \%$ was connected to the signal generator (R\&S SMF100A) and was used as the RF power transmitter. In Step 2 (Fig. 19(b)), the rectified DC voltage at the same distance $\mathrm{d}$ was measured at the output of the rectenna and the output

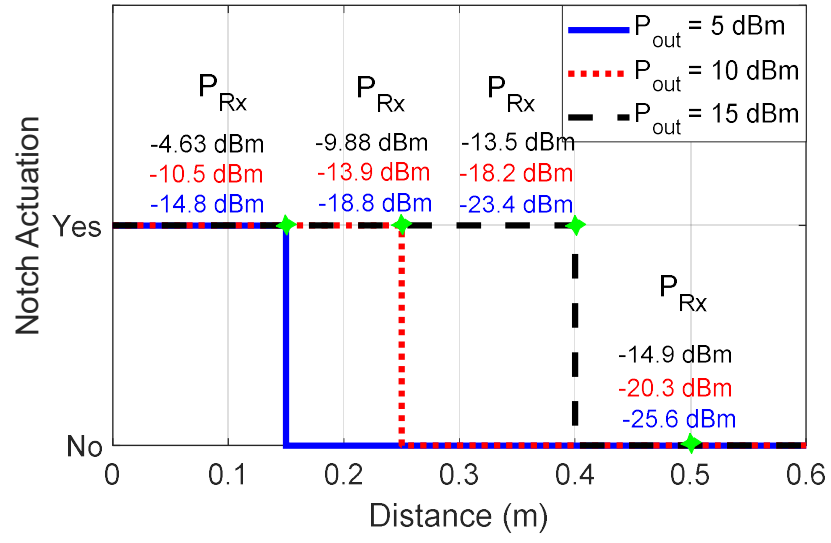

Fig. 20. Reconfigurable UWB antenna notch actuation for different Tx-Rx distances and different signal generator output power (Pout) levels. $\mathrm{P}_{\mathrm{Rx}}$ indicates the power at the input of the rectifier at different distances, as it was measured with a spectrum analyzer.

terminals of the passive DC-to-DC booster. When the rectified DC voltage rose above $V_{\text {rect }}=0.31 \mathrm{~V}$, the low power passive DC-to-DC boost converter elevated the output voltage to $3.3 \mathrm{~V}$ and successfully actuated the FET switch that is a constituent part of the reconfigurable UWB antenna. When the rectified voltage was lower than $0.3 \mathrm{~V}$, the boosted output voltage of the passive DC-to-DC booster dropped below $3 \mathrm{~V}$, the FET switch returned to the "OFF" state and the notch disappeared, in response. For rectified DC voltage higher than $0.31 \mathrm{~V}$ at the output of the RF-to-DC rectifier, an input RF power $\left(P_{i n}\right)$ higher than $-12 \mathrm{dBm}$ is required. This $P_{\text {in }}$ can be delivered to the rectifier by any antenna type.

In order to experimentally verify the expected response of the proposed dynamically reconfigurable UWB antenna (Fig. 18(a)), S-parameter measurements were taken (setup of Fig. 19(b)) in both the presence and the absence of an interfering 5.6 $\mathrm{GHz} \mathrm{RF}$ signal. Using the signal generator RF signals of varying power levels were created and transmitted using the patch antenna. The generated, unmodulated, single tone 5.6 $\mathrm{GHz}$ signal, was received and rectified from the EH system of the dynamically reconfigurable UWB antenna. The transmitter and receiver antennas, remained in each other's far field, during the entire set of measurements. The collected RF signal was rectified, boosted and was used to bias the packaged FET in order to dynamically actuate the notch on the $\left|\mathrm{S}_{11}\right|$ response of the UWB antenna. The testing was repeated for three different power levels while the distance was varied, and the measurement results are summarized in Fig. 20. Regarding the labeling used in Fig. 20, $P_{\text {out }}$ is the generated power from the signal generator, and $P_{R X}$ is the received power at the input of the rectifier. The actuation of the packaged FET switch (requires at least $3.3 \mathrm{~V}$ ) was made possible when $P_{R X}$ was higher than $-12 \mathrm{dBm}$.

The three power levels $\left(P_{\text {out }}\right)$ for which measurements were taken at 5,10 and $15 \mathrm{dBm}$. The dynamic reconfiguration of the UWB antenna was observed at distances $(d) 0.15,0.25$, and 0.4 $\mathrm{m}$ and this can be derived from Fig. 20. The maximum transmitted power of Unlicensed National Information Infrastructure(U-NII) at $5.6 \mathrm{GHz}$ as defined by FCC is limited to $+23 \mathrm{dBm}$ which means that the maximum distance for successful actuation could be increased accordingly. To verify 
the response speed of the dynamically reconfigurable notch a metallic screen was used to obstruct the transmitted signal. As a result, the FET switch was turned from "ON" state to "OFF" state practically instantly. The biasing of the FET switch, and therefore the reconfigurability was powered only from the wireless RF harvested energy, without using any external DC power source.

\section{Applications}

The UWB is generally divided into 5 band groups, and each band groups have 2 or 4 sub-bands. In standard UWB communication protocol, we see the usage of an entire band group and sub-bands are allocated for time sequencing signal transmission/reception [33]. One application of our approach is to use 1 sub-band in a band group for energy harvesting, and the remaining sub-bands for low data rate communication application like in battery-less autonomous wireless communication nodes. Practical applications of EH system integrated with UWB radiators can be found in the implementation of battery-less UWB RFIDs used for indoor localization. Moreover, as an improvement in UWB antennas with permanent stop bands, this work shows that a battery-less system can be connected to a UWB antenna to turn the stop band operation ON or OFF dynamically and wirelessly.

\section{CONCLUSION}

A dynamically reconfigurable UWB antenna integrated with an energy harvesting system in a dual-layer SoP approach has been presented. In order to enable the powering of the electric switch from the harvested wireless RF energy originating from interfering signals at $5.6 \mathrm{GHz}$, a very low power GaAs FET switch was chosen. The energy harvesting system is designed to collect power from interfering signals in the congested band around $5.6 \mathrm{GHz}$. It consists of a PIFA cascaded with a very compact RF-to-DC rectifier with a recorded efficiency of $40 \%$ at $-10 \mathrm{dBm}$. The final stage is a passive DC-to-DC boost converter based on the Armstrong oscillator which elevates the rectified DC voltage to the required $3.3 \mathrm{~V}$ which is the minimum voltage needed for the actuation of the packaged FET switch. For the designed energy harvesting system, the minimum RF power that is needed at the input of the rectifier is $-12 \mathrm{dBm}$. At collected power levels higher than $-12 \mathrm{dBm}$, the FET switch of the reconfigurable UWB antenna is set to the "ON" state, causing a notch-band around 5.6 GHz. As soon as the $5.6 \mathrm{GHz}$ interfering signal is eliminated, the notch-band is immediately cancelled and it appears again dynamically when the received power goes higher than the $-12 \mathrm{dBm}$ threshold, without the need of any external DC source, since the FET switch is powered only from the harvested energy carried by the collected interfering $5.6 \mathrm{GHz}$ signals. In the absence of an interfering high power $5.6 \mathrm{GHz}$ signal, the presence of the extended narrow band PIFA and the miniaturized EH system do not disturb the wideband standard operation of the UWB antenna in neither reception nor transmission mode.

The proposed UWB antenna is a microstrip-fed monopole with an embedded elliptical slot. A quarter wavelength linear stub is placed in the elliptical slot and a GaAs FET switch serves as the electric switch that connects and disconnects the stub causing the creation and the elimination of the notch-band, respectively. The UWB antenna is fabricated on a Duroid substrate. The narrow band EH system is implemented on a second Duroid substrate and it shares a common RF ground with the UWB antenna. The harvested energy has a direct relationship with the antenna gain and overall footprint. However, for the implementation of the proposed SoP reconfigurable UWB antenna, we consider a miniaturized $\mathrm{EH}$ system. Therefore, a compact PIFA with omnidirectional radiation patterns is used as the rectenna module cascaded with a very compact RF-to-DC rectifier using a voltage-doubler topology.

To the best of our knowledge a dynamically reconfigurable UWB antenna with switching operation powered entirely from $\mathrm{RF}$ harvested energy is presented for the first time. Considering the FCC EIRP constraints for both UWB and WLAN systems the proposed SoP UWB antenna can be an excellent candidate for Wireless Personal Area Network (WPAN) applications that require improved SNR, since it dynamically suppresses the interfering signals in the congested frequency band around 5.6 $\mathrm{GHz}$. SoP implementations of compact EH systems with UWB antennas can also be used for UWB RFIDs used for indoor localization.

\section{ACKNOWLEDGMENT}

This work was co-funded by the European Regional Development Fund and the Republic of Cyprus through the Research and Innovation Foundation, under the project EXCELLENCE/1216/376 (SWITCH).

\section{REFERENCES}

[1] I. Y. Immoreev, "Practical applications of UWB technology," in IEEE Aerosp. Electron. Syst. Mag., vol. 25, no. 2, pp. 36-42, Feb. 2010.

[2] G. Adamiuk, T. Zwick, and W. Wiesbeck, "UWB Antennas for Communication Systems," Proc. IEEE, vol. 100, no. 7, pp. 2308-2321, 2012.

[3] X. Zhao, S. Riaz and S. Geng, "A Reconfigurable MIMO/UWB MIMO Antenna for Cognitive Radio Applications," in IEEE Access, vol. 7, pp. 46739-46747, April 2019.

[4] S. Doddipalli and A. Kothari, "Compact UWB Antenna With Integrated Triple Notch Bands for WBAN Applications," in IEEE Access, vol. 7, pp. 183-190, Dec. 2018.

[5] W. Shao, A. Edalati, T. R. McCollough and W. J. McCollough, "A TimeDomain Measurement System for UWB Microwave Imaging," in IEEE Trans. Microw. Theory Techn., vol. 66, no. 5, pp. 2265-2275, May 2018.

[6] F. Qi et al., "Position-Information-Indexed Classifier for Improved Through-Wall Detection and Classification of Human Activities Using UWB Bio-Radar," in IEEE Antennas Wireless Propag. Lett., vol. 18, no. 3, pp. 437-441, March 2019.

[7] M. Rahman and J.-D. Park, "The smallest form factor UWB antenna with quintuple rejection bands for IoT applications utilizing RSRR and RCSRR,', Sens., vol. 18, no. 3, p. 911, 2018

[8] J. Liang, X. Liu and K. Liao, "Soil Moisture Retrieval Using UWB Echoes via Fuzzy Logic and Machine Learning," in IEEE Internet Things J., vol. 5, no. 5, pp. 3344-3352, Oct. 2018.

[9] Revision of Part 15 of the Commission's Rules Regarding UltraWideband Transmission Systems, FCC, Washington, DC, USA, 2002.

[10] S. Nikolaou, M. Davidović, M. Nikolić, and P. Vryonides, "Triple notch UWB antenna controlled by three types of resonators," in IEEE Int. Symp. Antennas Propag. (APS), 2011, pp. 1478-1481.

[11] C. Saha, L. A. Shaik, R. Muntha, Y. M. M. Antar and J. Y. Siddiqui, "A Dual Reconfigurable Printed Antenna: Design Concept and Experimental Realization," in IEEE Antennas Propag. Mag., vol. 60, no. 3, pp. 66-74, June 2018 .

[12] M.S. Alam, A. Abbosh, "Reconfigurable band-rejection antenna for ultra-wideband applications", in IET Microw. Antennas Propag., 9;12(2):195-202, Oct. 2017. 
[13] M. C. Tang, H. Wang, T. Deng, and R. W. Ziolkowski, "Compact Planar Ultrawideband Antennas With Continuously Tunable, Independent Band-Notched Filters," in IEEE Trans. Antennas Propag., vol. 64, no. 8, pp. 3292-3301, Aug. 2016.

[14] S. Nikolaou, N. D. Kingsley, G. E. Ponchak, J. Papapolymerou, and M. M. Tentzeris, "UWB Elliptical Monopoles With a Reconfigurable Band Notch Using MEMS Switches Actuated Without Bias Lines," in IEEE Trans. Antennas Propag., vol. 57, no. 8, pp. 2242-2251, Aug. 2009.

[15] A. K. Horestani, Z. Shaterian, J. Naqui, F. Martín and C. Fumeaux, "Reconfigurable and Tunable S-Shaped Split-Ring Resonators and Application in Band-Notched UWB Antennas," in IEEE Trans. Antennas Propag., vol. 64, no. 9, pp. 3766-3776, Sept. 2016.

[16] T. Aboufoul, A. Alomainy and C. Parini, "Reconfiguring UWB Monopole Antenna for Cognitive Radio Applications Using GaAs FET Switches," in IEEE Antennas Wireless Propag. Lett., vol. 11, pp. 392394, April 2012.

[17] X. Yang, J. Lin, G. Chen and F. Kong, "Frequency Reconfigurable Antenna for Wireless Communications Using GaAs FET Switch," in IEEE Antennas Wireless Propag. Lett., vol. 14, pp. 807-810, Dec. 2015.

[18] Skyworks. Solutions. (February). Schottkey diode [online]. Available: http://www.skyworksinc.com/Product/319/SKY13298-360LF, Accessed on: Feb. 2019.

[19] S. Nikolaou and M. A. B. Abbasi, "Design and Development of a Compact UWB Monopole Antenna With Easily-Controllable Return Loss," in IEEE Trans. Antennas Propag., vol. 65, no. 4, pp. 2063-2067, April 2017.

[20] M. Ali, R. A. Sadler and G. J. Hayes, "A uniquely packaged internal inverted-F antenna for Bluetooth or wireless LAN application," in IEEE Antenna Wireless Com. Lett., vol. 1, pp. 5-7, 2002.

[21] C. Soras, M. Karaboikis, G. Tsachtsiris and V. Makios, "Analysis and design of an inverted-F antenna printed on a PCMCIA card for the 2.4 GHz ISM band", in IEEE Antennas Propag. Mag., vol. 44, no. 1, pp. 37 44, Feb. 2002.

[22] Skyworks. Solutions. (February). Schottkey diode [online]. Available: http://www.skyworksinc.com/Product/511/SMS7630_Series, Accessed on: Feb. 2019.

[23] P. Lu, X.-S. Yang, J.-L. Li, and B.-Z. Wang, "Polarization reconfigurable broadband rectenna with tunable matching network for microwave power transmission," in IEEE Trans. Antennas Propag., vol. 64, no. 3, pp. 1136-1141, March 2016.

[24] D. Wang and R. Negra, "Design of a dual-band rectifier for wireless power transmission," in Proc. IEEE Wirel. Power Transf. (WPT), Perugia, Italy , pp. 127-130, May 2013.

[25] M. ur Rehman, W. Ahmad and W. T. Khan, "Highly efficient dual band $2.45 / 5.85 \mathrm{GHz}$ rectifier for RF energy harvesting applications in ISM band," in IEEE Asia Pacific Microw. Conf. (APMC), Kuala Lumpar, 2017, pp. 150-153.

[26] Q. Zhang, J. Ou, Z. Wu and H. Tan, "Novel Microwave Rectifier Optimizing Method and Its Application in Rectenna Designs," in IEEE Access, vol. 6, pp. 53557-53565, Sep. 2018.

[27] M. Kanoun, D. Cordeau, J. Paillot, H. Mnif and M. Loulou, "A 5.9 GHz RF rectifier for wireless power transmission applications," $201724 \mathrm{th}$ IEEE International Conference on Electronics, Circuits and Systems (ICECS), Batumi, 2017, pp. 385-388.

[28] H. Lee and J. Lee, "Optimization of a 5.8-GHz rectifier considering ripple amplitude and DC-voltage pattern," in Proc. IEEE Wirel. Power Transf. (WPT), Jeju, 2014, pp. 212-215.

[29] S. D. Assimonis, S. Daskalakis and A. Bletsas, "Efficient RF harvesting for low-power input with low-cost lossy substrate rectenna grid," in IEEE RFID Techn. Appli. Conf. (RFID-TA), Tampere, 2014, pp. 1-6.

[30] Coilcraft. (February). Fixed Inductors 0402CS [online]. Available: https://eu.mouser.com/datasheet/2/597/0402cs-253326.pdf, Accessed on: Feb. 2016.

[31] Coilcraft. (February). LPR6235 Coupled Inductors for Step-Up \& Flyback Applications [online]. Available: https://www.coilcraft.com/pdfs/lpr6235.pdf, Accessed on: Feb. 2019.

[32] K.-L. Wong, "Compact and broadband microstrip antennas," vol. 168. New York: John Wiley \& Sons, INC., 2004.

[33] ECMA-368 "High Rate Ultra Wideband PHY and MAC Standard," 3rd Edition, December 2008 Accessed on: September, 27, 2019. [Online]. https://www.ecma-international.org/publications/files/ECMAST/ECMA-368.pdf 